
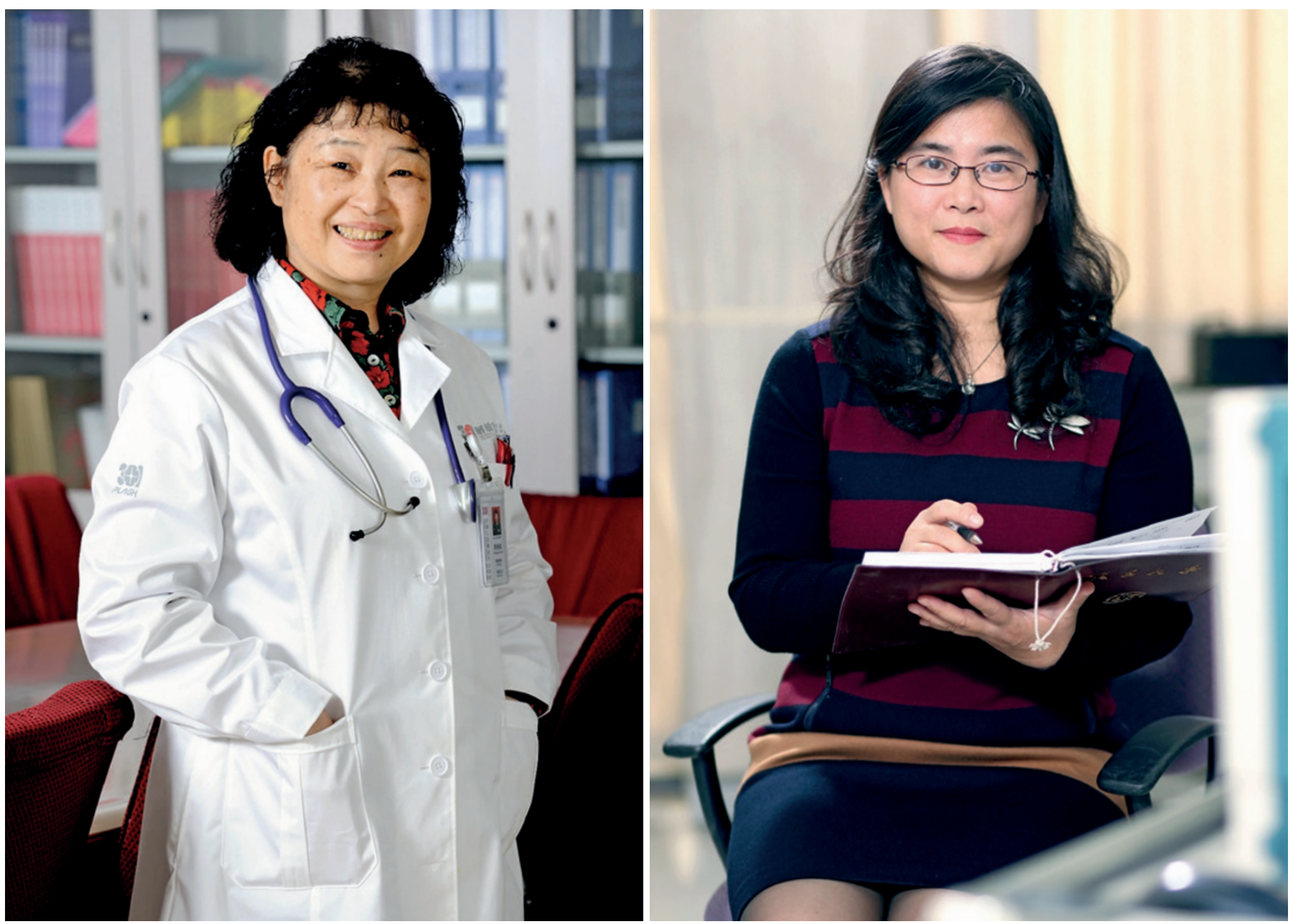

\title{
Q\&A Chen Xiangmei and Zeng Xuan
} Times are changing

Two women, 18 years apart, describe their experiences within China's research system. Chen Xiangmei (pictured, left) received her MD from Kitasato University, Tokyo, in 1986 and is now the director of the State Key Laboratory of Kidney Diseases of China at the PLA General Hospital in Beijing. Zeng Xuan (pictured, right) received her PhD in semiconductor physics from Fudan University, Shanghai, in 1997 and is now a professor at Fudan's School of Microelectronics.

In China's high schools, there are usually more girls studying languages and humanities than science and maths, and there is a stigma attached to the term 'female PhD' such that it has become a derogatory way of referring to an educated woman who is focusing on her career. A lot of parents tell their daughters that girls are not as good at science as boys. Have you ever faced this type of pressure?

Chen Treating women as if they are intellectually inferior to men has thousands of years of history in China's major ethnic groups, such as the Han. There are many families that hold onto this traditional line of thinking, especially in the less developed parts of the country. Often, such families would choose to support their sons to pursue a career that requires more years of education. The situation is usually more balanced in large, economically dynamic cities and in educated families. The percentage of female students at top universities is increasing, and a substantial percentage of women are majoring in science or maths.

In 2001, I became a chief scientist funded by the 973 Programme, also known as the National Basic Research Programme, which is a prestigious funding scheme in China. I was the only female chief scientist of a 973 Programme in 2001 . We need more women at the top level of society, not just in science, but also in the army, in the government and every aspect of society, otherwise we are wasting talent.
Zeng I was once that rare species: a female science $\mathrm{PhD}$ candidate! My interest in physics started when I was in high school in the 1980s. I was lucky that my parents never discouraged me from pursuing science. I read about the female physicist Xie Xide, who was president of Fudan University in Shanghai at the time. Scientists were like rock stars in the 1980s in China, and we were all familiar with the saying: 'Master math and science, then you have nothing to fear wherever you go'.

When I arrived as an undergraduate at Fudan University, my first choice was biomedical electronics but I was transferred to microelectronics. I was worried initially, but then I learnt that the microelectronics major 
had been created by Xie, which inspired me to work really hard. I was fascinated from the first moment that I had access to computers and integrated circuits in the lab during my second year. I was fortunate to have many great mentors who nurtured my interest. No one discouraged me from studying science because I am a woman.

\section{Are there the same opportunities for men and} women to become scientists in China?

Chen After the People's Republic of China was founded in 1949, women in China were encouraged to work and were treated as equals to men legally, so I think there are the same opportunities for men and women to become scientists in China. But in real life, at least until now, women tend to spend more time raising children and taking care of their families.

Zeng Among the top high-school students, undergraduate students and graduate students in life sciences and medicine, women make up a similar percentage to men. That's less true in maths and physics, where men are still in the majority. So in many fields, the opportunity to become a scientist is equal for the sexes in China. At the very top, however, there are far fewer women. I think that is going to change as society becomes more aware of gender inequality (see 'The global picture of women in further education').

\section{What is the availability of career breaks, maternity packages and flexible working for scientists in China?}

Chen Nationwide, the minimum paid maternity leave is 14 weeks, but women who have babies later in life could have an additional 15 or 30 days depending on the region in which they work. Women scientists have the same maternity packages as women in other professions, but it can be a real challenge for them to catch up with everyone else when they return to work.

Zeng With regard to maternity, instead of providing a longer period of maternity leave, it's more important for a female scientist to have access to flexible working. An extended break can be detrimental to a scientist's career, but flexible working arrangements are still rare in China. Grandparents often step in to take care of the baby when a mother returns to work.

I have been a visiting scholar to several US universities and I was told that when female researchers are being evaluated for tenure, they are given two extra years in their evaluation period to compensate for time lost while raising children. Similar policies are also appearing in the national funding programmes in China, but there is not anything at the institutional level yet.

What about paternity leave - how common is it for men in China?

Chen It would be great if men in China would take a larger portion of the parental leave! I've

\section{THE GLOBAL PICTURE OF WOMEN IN FURTHER EDUCATION}

In the past two decades, China has boosted its share of women studying in tertiary education and, after overtaking its neighbour Japan in 2004, it is now in line with world averages.

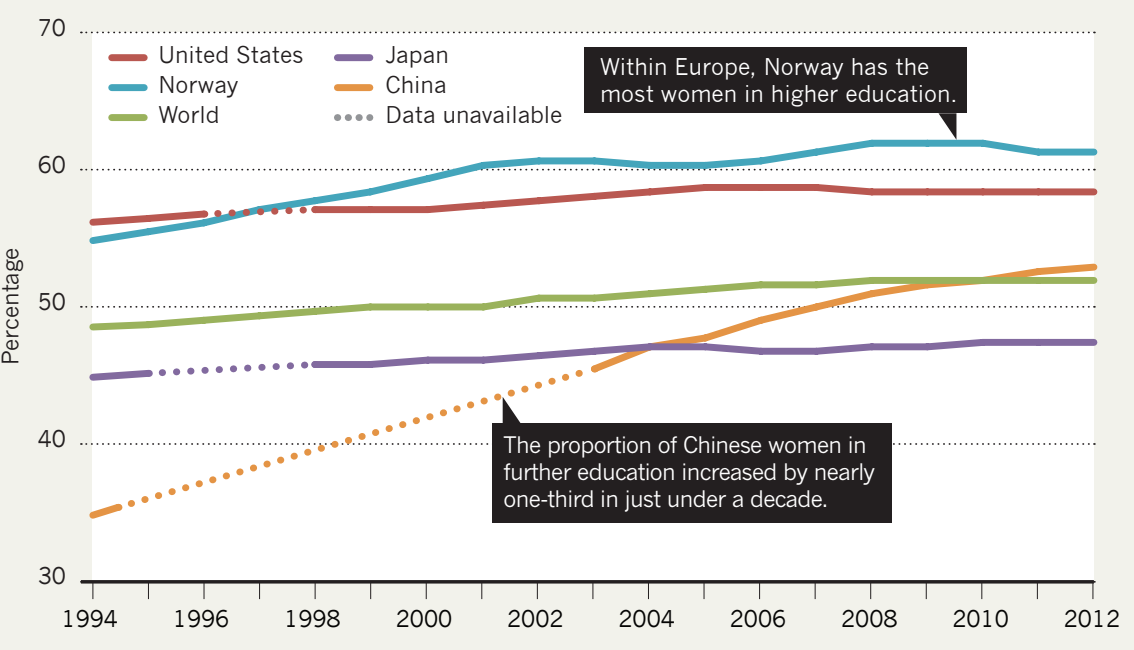

heard of men taking paternity leave to take care of their newborns, but I've never met anybody who has done so in real life. Traditional values still hold sway in China, so even if a man was willing to take time off to care for his baby, he would probably face "In many fields, the opportunity to become a scientist is equal for the sexes in China." social pressure from others. I hope that parents share the responsibility equally to take care of their children, but in reality, it is women who end up doing more.

Zeng Men can take a few days of paid paternity leave immediately after the baby is born, but I, too, have never met any Chinese men who took substantial paternity leave. It seems that Chinese men are holding onto traditional values very tightly.

\section{Are there biases in research evaluation that disadvantage women?}

Chen In most of China's research-evaluation systems, women are treated exactly the same as men, but women who take time off to have children are often disadvantaged compared with men of the same age. So the National Natural Science Foundation of China youth programme changed its application age limit a few years ago to allow female scientists under 40 and male scientists under 35 to apply for its funding. This is a great way to mitigate the disadvantage faced by women.

Zeng I don't think there are any policy biases in research evaluation that actively disadvantage women, but family responsibility can sometimes slow a female scientist down. When I finished my $\mathrm{PhD}$, there was a gap in professors of both sexes because the Cultural Revolution put higher education on hold for a decade and many new graduates chose to study abroad.
Fudan University's administration trained the young researchers to become lecturers and helped them to establish their own laboratories. I was lucky to take advantage of that.

What do you think would be the best way to encourage more women to pursue science? Chen I think the best change would be to move away from traditional values. Young people with potential and who have good career prospects should receive support from their significant others and family regardless of their gender. Also, I tell all my students that if they want to become successful physicians, they should spend more time and energy on their work. It is also vital that they communicate effectively with their partners about what their jobs will require so they can share household duties. With support from their families, women can become outstanding medical scientists.

Zeng I am concerned that so few youngsters in China today aspire to be scientists. That is partly because teachers do so little to stimulate interest in maths and science, especially anything that directly appeals to girls. Students are more focused on simply getting good grades. The lack of encouragement at an early age may explain why there are very few women in maths and physical sciences in higher education. When I was studying geometry in high school, students who could draw neat lines to solve geometry problems were deemed smart and those who could not were deemed not smart. Years later, I met a mathematician in college and learned that the ability to draw such lines is not a good measure of ability: analytical geometry is better. We need teaching methods that will nurture girls' interest in maths and physical sciences. 